Presented at the Conference on the Properties of Nuclei Far from the Region of Beta Stability, Leysin,

Switzerland, Aug. 31 -Sept. 4, 1970
UCRL-19957

Preprint

CoNt-700815--3

\title{
SEARCH FOR SUPERHEAVY ELEMENTS IN NATURE BY DETECTION
}

OF EVENTS WITH LARGE NUMBERS OF NEUTRONS

E. Cheifetz, E. R. Giusti, H. R. Bowman, R. C. Jared, J. B. Hunter and S. G. Thompson

August 1970

AEC Contract No. W $-7405-$ eng -48
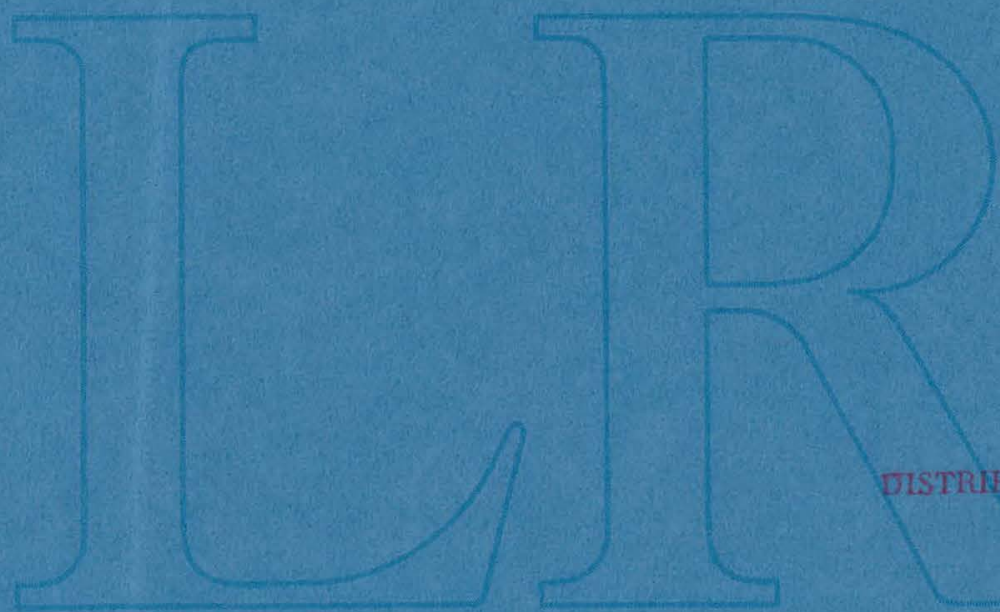


\section{DISCLAIMER}

This report was prepared as an account of work sponsored by an agency of the United States Government. Neither the United States Government nor any agency Thereof, nor any of their employees, makes any warranty, express or implied, or assumes any legal liability or responsibility for the accuracy, completeness, or usefulness of any information, apparatus, product, or process disclosed, or represents that its use would not infringe privately owned rights. Reference herein to any specific commercial product, process, or service by trade name, trademark, manufacturer, or otherwise does not necessarily constitute or imply its endorsement, recommendation, or favoring by the United States Government or any agency thereof. The views and opinions of authors expressed herein do not necessarily state or reflect those of the United States Government or any agency thereof. 


\section{DISCLAIMER}

Portions of this document may be illegible in electronic image products. Images are produced from the best available original document. 
SEARCH FOR SUPERHEAVY ELEMENTS IN NATURE BY DETECTION OF

EVENTS WITH 'LARGE NUMBERS OF' NEUTRONS ${ }^{*}$

E. Cheifetz, E. R. Giusti, H. R. Bowman, R. C. Jared, J. B. Hunter, and

S. G. Thompson

Lawrence Radiation Laboratory

University of California

Berkeley, California 94720

\section{ABSTRACT}

Some preliminary results are reported on a search for the presence of "superheavy elements" in nature. Large samples (10-50 kg) of various substances including $\mathrm{W}$ and $\mathrm{Pb}$ ores as WPl7 as manganese nodules were examined for the presence of spontaneous fission events in which large numbers of neutrons are emitted. The method utilized a large Gd loaded liquid scintillator with 60-70\% efficiency for detecting neutrons. The system was located in a tunnel of depth $\sim 275$ meters in order to reduce interference from cosmic rays. In the materials tested no events above background were detected. This limit corresponds to half lives in the region $10^{23}$ years relative to the principle component of the samples. INTRODUCTION

In recent years various estimates and calculations have been made which suggest the possibility that nuclei having atomic numbers in the region 108-114 may be sufficiently stable to exist in nature. These nuclei. are expected to der.ay either directly by spontaneous fission or indirectly by other modes of decay to give products which would then undergo spontaneous fission.

Fork performed under the auspices of the U. S. Atomic Energy Commission. 
It is expected that the spontanchis assin of these "superintidy nuclei" would be accompanied on the average by ensosion of about ter neutrons. The emission of such a large number of neutrons from each sirjie fission event is then a very distinctive indicator of the presence of these elements because this property does not occur in ary of the presently known spontaneously fissioning species in nature. Furthermore, these evaporated neutrons would have average energies in the range $1-3 \mathrm{MeV}$ and thus would be able to escape the sample and enter the counting chamber. Consequently large amounts of heavy materials can be examined with great sensitivity.

The use of a large liquid scintiliator is a sensitive and corvenient method for detecting events in which large numbers of neutrons are emitted. The efficiency for detecting neutrons is high especially when the scintillator contains an element such as gadolinium which has a very large sross section for neutron capture (46000 barns). Finally, the liquid scintillator provides a natural means of detecting many neutrons from single events because it makes use of the wide variation and separation in thermalizfition times; i.e. the individual neutrons are separated according to time oi thermalization and are then captured to produce the photons and Iight which is seen by the photomultipliers.

In the preliminary wurk repurled hepe we have used a system arvolvans a liquid scintillator to search for superheavy elements in several materials. A number of other materials will be examined before the work is completed. 2. DESCRIPTION OF THE DETECTION METHOD

The neutrons are detected by a large gadolinium loaded liquio scintillator with the capability of measuring neutrons with high efficiency. A schematic view of the detector system is shown in Fig. I. Its main body is a tank with dimensions $62 \times 62 \times 125 \mathrm{~cm}$ which holas a liquid consisting of toluene solvent, $\sim 8 \mathrm{~g} / 1$ gadolinium octoate, $0.1 \mathrm{~g} .1$ POPOP and $5 \mathrm{~g} / \mathrm{l}$ 


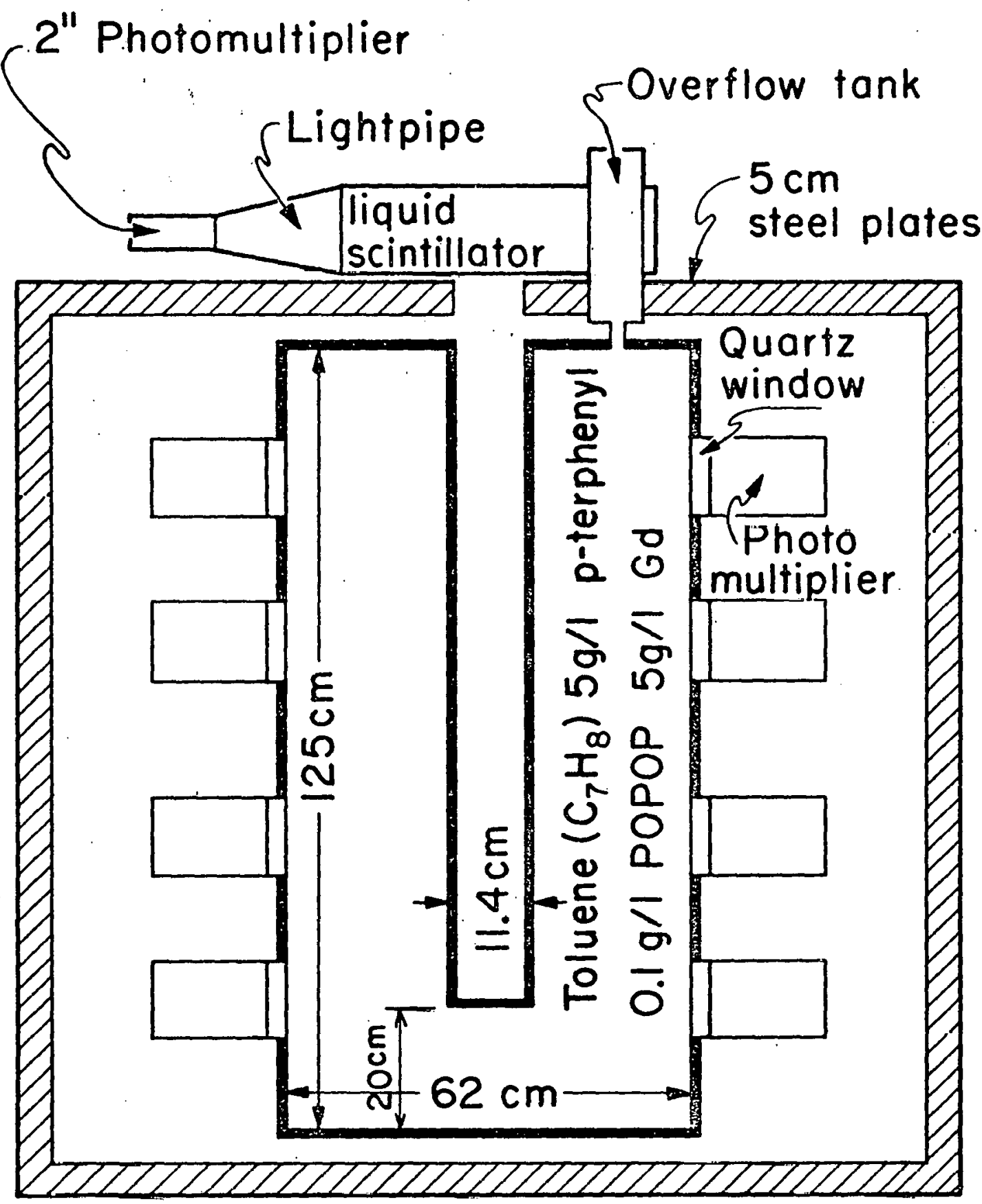


p-terpheny 1. Sixteen 5-inch Dumont No. 6364 pinuomitibiciers are mounteä'on glass viewing ports on two walis of the chamber. The inner'walls of the chamber are painted with white reflective coating. A tube for holding the samples is located at the center of the chamber and has the dimensions of $11.4 \mathrm{~cm}$ diameter and $105 \mathrm{~cm}$ depth. The system is very similar to some described already in the literature. ${ }^{\text {l) }}$

Neutrons produced by any source placed at the center of the chamber enter the liquid and are thermalized by collisions with the hydrogen in the solution and eventually are either captured by the gadolinilim or leak out of the tank. The $(n, \gamma)$ reaction in gadolinium prodices $\sim 9 \mathrm{MeV}$ of gamma energy, the energy usually being shared by several gamma rays. The electrons created by the reaction of these gamma rays with the liquid produce scintillations which are seen by a. few of the photomultipliers.

The distribution in time for neutron capture is broad and has a peak at about $10 \mathrm{\mu sec}$ after the neutrons are emitted. About $90 \%$ of all the neutrons are captured within $1-36 \mathrm{\mu sec}$ after their production. In this way individual members of a burst of energetic neutrons ( $\sim$ I MeV) are separated in time for convenient electronic multiplicity counting.

3. ELECTRONICS

A simplified block diagram of the electronics is shown. in Fig. 2. The photomiltiplier pulses are summed in two banks ( 8 photomultipliers in each). A "tank pulse" is obtained when coincident pulses are observed from banks $A$ and $B$ and when the linear sum of all photo multiplier outputs corresponds in pulse height to an energy. greater than $1 \mathrm{MeV}$. This signal has the significance that the light must be seen by at least two photomultipliers and have a sum amplitude corresponding to an energy greater than $I \mathrm{MeV}$. Since at least two photomultipliers must give a signal the effect of random noise 
from individual tubes is minimized. A "tank pulse" triggers, after a 0.5. usec delay, a 36 usec gate. " (The delay is to aniure that 211 of the prompt gamma rays from a fission event have been cmitted.) During the 36 usec gate interval all tank puises are countei by a sciller. At the end of the 36 usec period the digital information in the scaler is converter to analog pulse heights and transferred to a pulse height analyze:. Then the scaler is reset. The next tank pulse defines a new 36 usec gate interval. A spectrum of multiplicity in the range 0-15 is thus obtained in a pulse height analyzer. The system is capable of monitoring a burst of neutrons where the trigger can be activated either by the prompt $\gamma$-rays or the first neutron captured. The circuits shown by dotted lines in Fig. 2 was added in the later experiments to remove events that had cosmic rays in coincidence and will be discussed later.

4. OPERATION OF THE SYSTEM

The efficiency of the system was checked at regular intervals by placing a weak ${ }^{252} \mathrm{Cf}$ spontaneous fission source in the center of the tank and triggering the $36 \mu \mathrm{sec}$ gate by the fission events (using a small solid state detector to detect the fragments). The multiplicity distribution obtained in this manner for 25,000 fission events is shown in Fig. 3 . Its mean value is $\bar{n}=2.44$. This yields an efficiency of $65.5 \%$ for detection of each neutron (using 3.72 as the average number of neutrons emitted in ${ }^{252}$ (f fission).

Long terin stability and continuous monitoring of the system which is necessary for this type of an experiment was obtained in three ways: 1) The singles counting rate of tank pulses was recorded every 2 sec jy a chart rionrder and showed the system to be very stable. 2) The data from the multi-channel analyzer were printed out automatically et regular intervals 


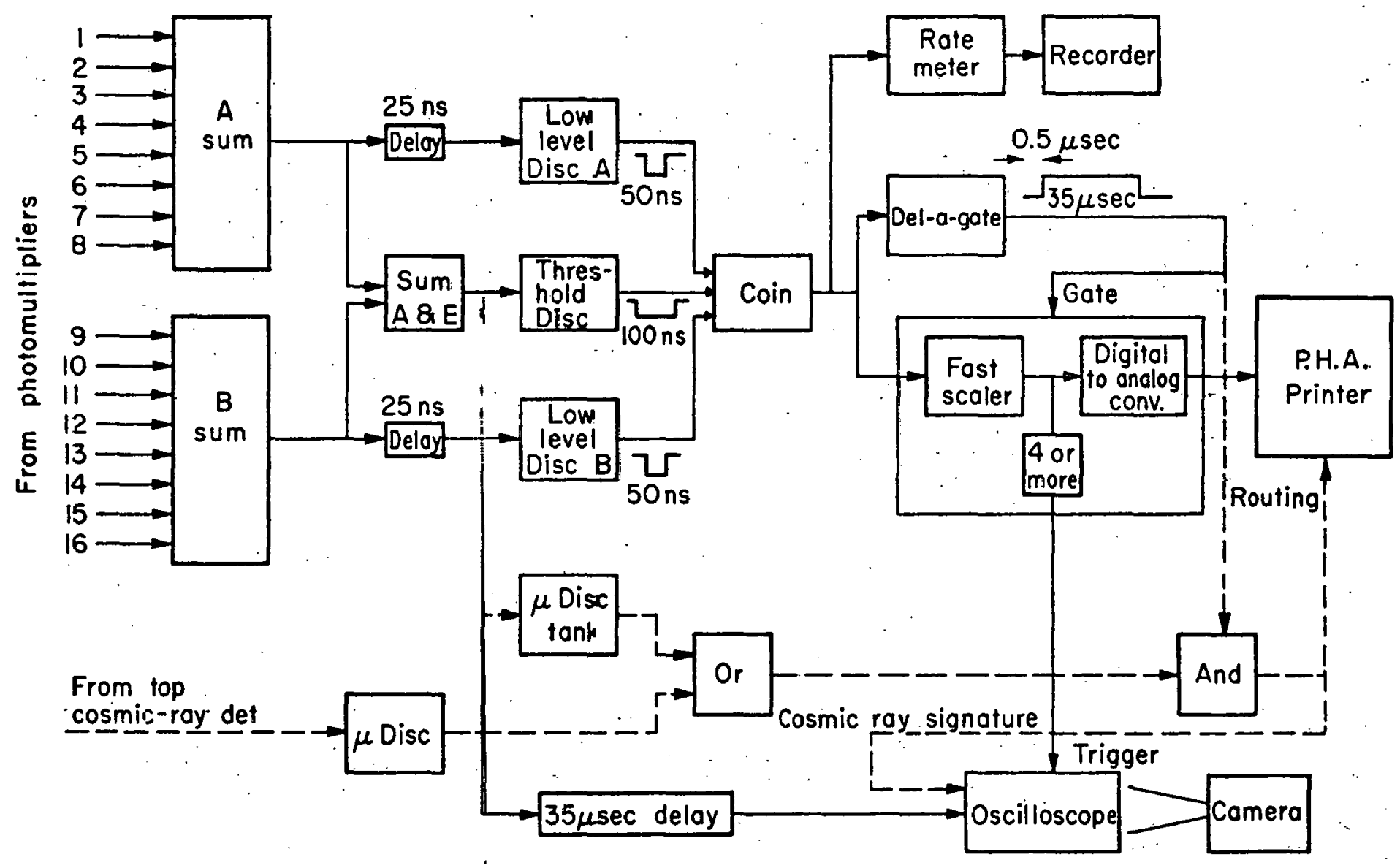

XBL706-325I 


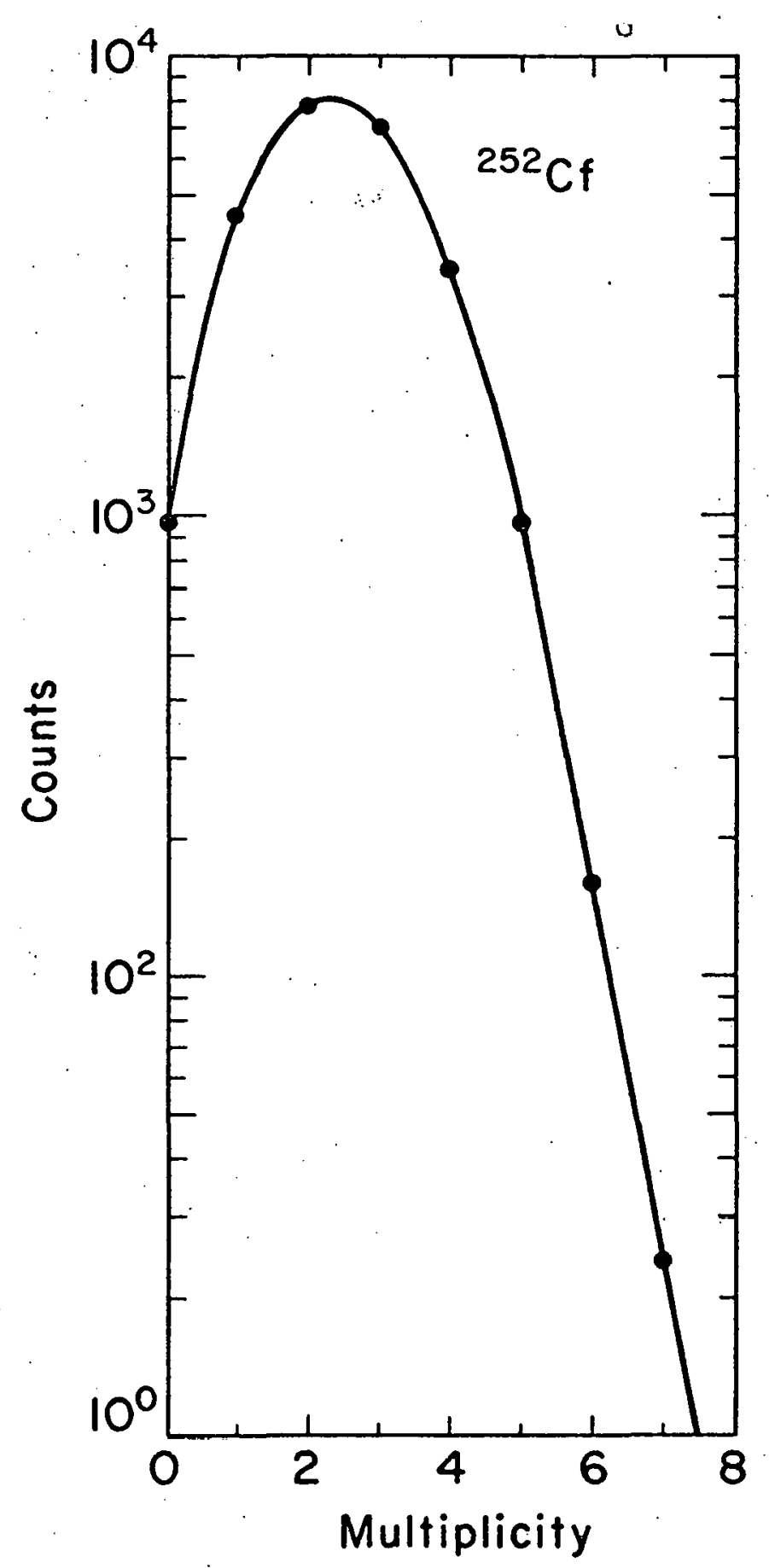

XBL 706-3249

Fig. 3. The multiplicity distribution observed with a ${ }^{252} \mathrm{Cf}$ source placed in. the center of the chamber. The $36 \mu \mathrm{sec}$ gate was triggered by a fission fragment detector. The average multiplicity was 2.44 , i.e. the effisiency $=2.44 / \bar{v}=65.5 \% ;(\bar{v}=3.72)$. 
and the multiplicity distributions were found to be consistent (within statistical fluctuations). 3) In recent experiments photographs were made of: the tank pulses that appeared during the $36 \mu$ sec gate, whenever an event having a multiplicity of four or more occurred. In principle these events can be checked to be certain they have a normal time distribution. However, as yet, the photographic equipment has not been operating satisfactorily.

When the system operates with the neutron tank pulse as the main trigger, it is sensitive to the environmental radiation which consists of gamma rays from natural sources (e.g. U, Th, and $K$ ) and cosmic rays and the products of their reactions in matter. The gamma rays that arise from natural sources appear in general as single random pulses. Accidental coincidences between these random pulses yield a distribution which is represented by a Poisson probability function.

$$
P(N)=\frac{8.64 \times 10^{4}(\mathrm{CT})^{N+1} \exp (-\mathrm{CT})}{(N ! \cdot T)}
$$

where $P(N)$ is the number of events observed per day appearing to have a multiplicity $\mathrm{N}$ with a single random tank pulse rate of $\mathrm{C}$ (per sec) and a gate length of $\mathrm{T}(\mathrm{sec})$. At the operatine count rate of 600 counts/3ec less than 1 event per day appearing as multiplicity four or more can be expected. 5. RESULTS

The results of the multiplicity distributions measured on samples of lead ore and tungsten in metallic form are shown in Figs. 4 and 5 . In both cases events with high multiplicities were observed at a rate that could not be accounted for by the expected random occurrence of high'multiplicity events. The rate of events with given multiplicity expected from probability considerations is indicated in the figures by the dark lines and was 


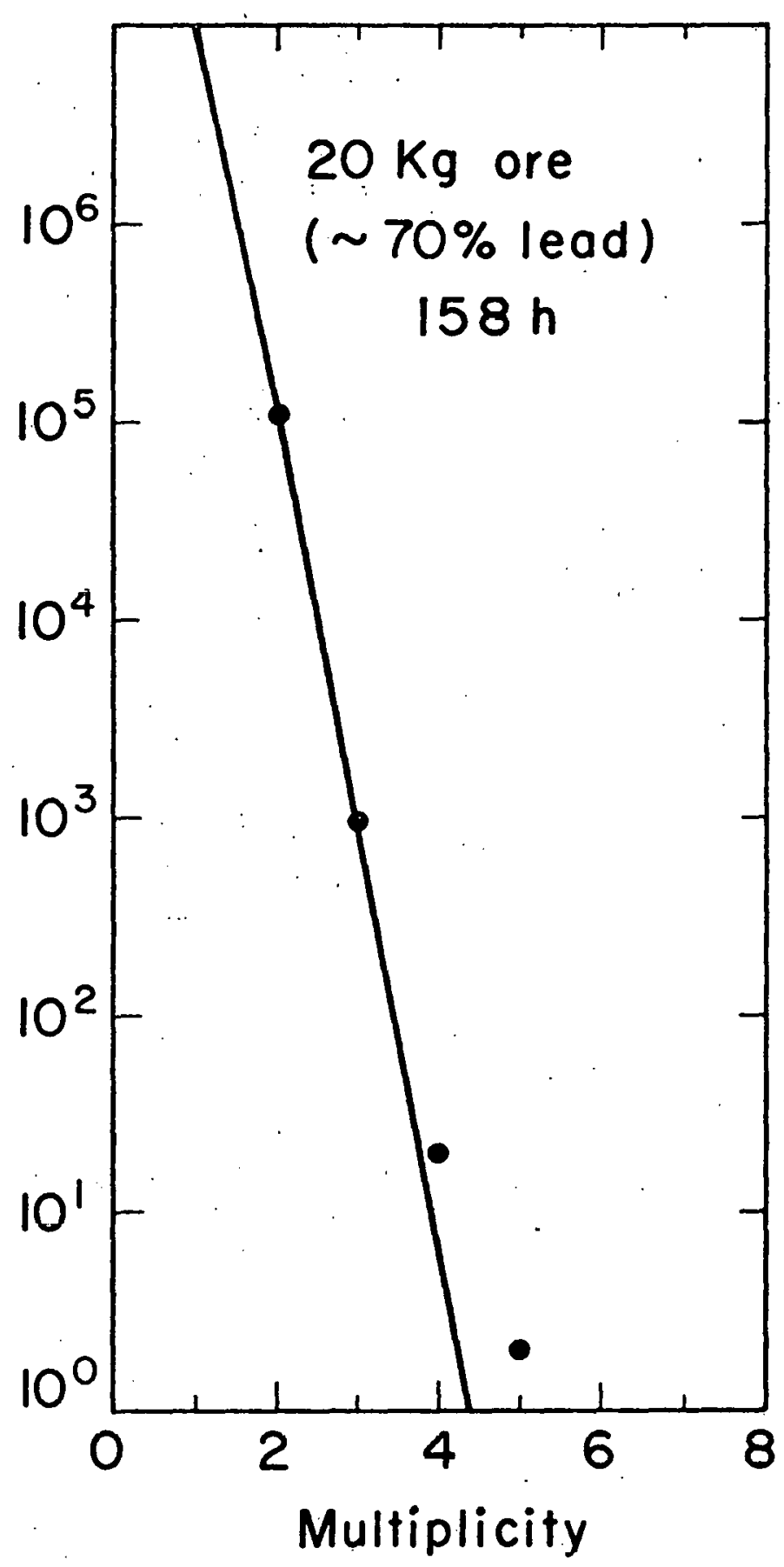

XBL706-3248

Fig. 4, The multiplicity distribution obtained with a lead ore sauple. The dark line represents the multiplicities expected on the basis. of pribability considerations and the dots represent the experimental results. 


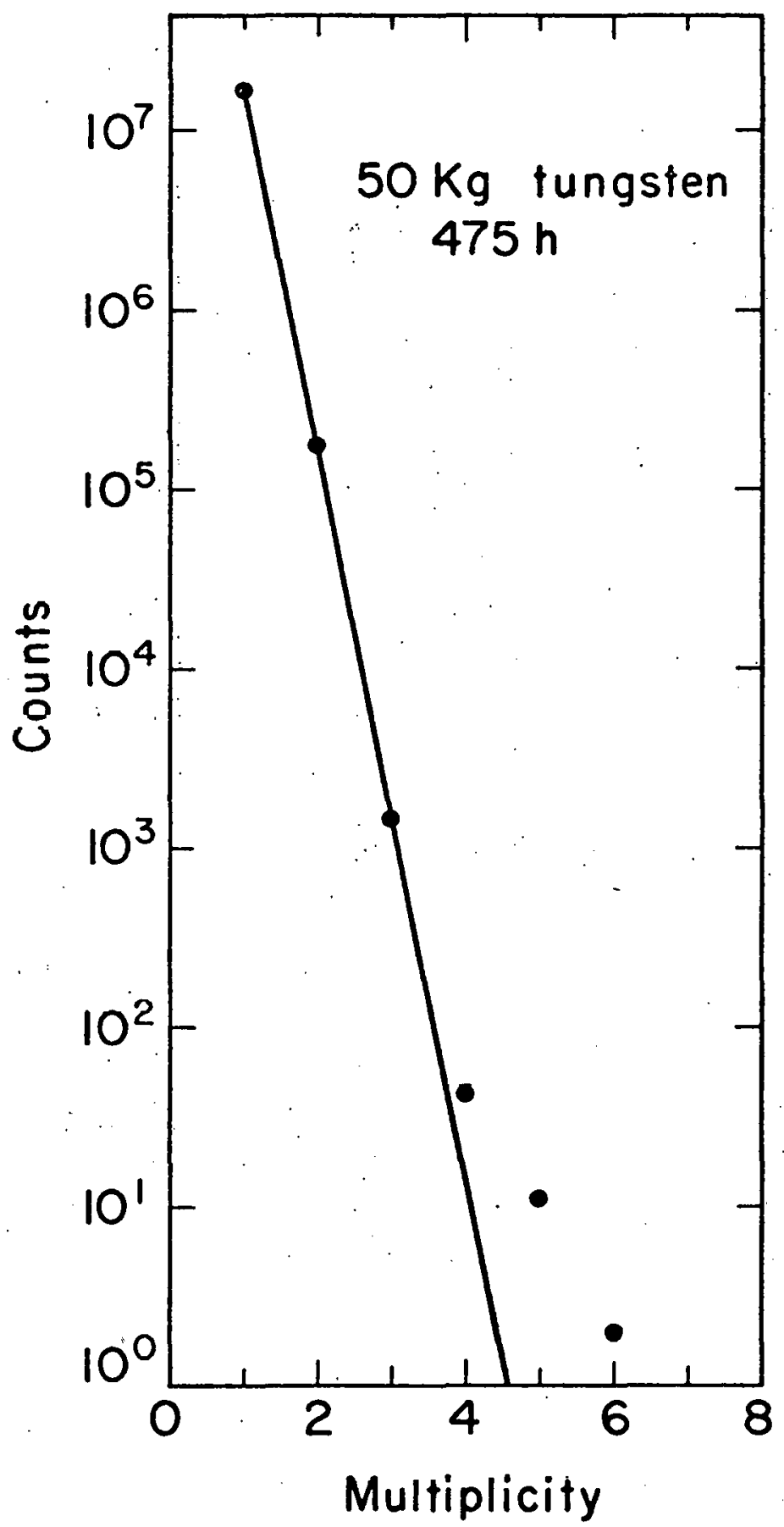

XBL706-3247

Fig. 5. The multiplicity distribution obtained with a sample of purified tungsten metal. The dots represent the experimental results and the dark lines the expected random behavior. 
calculated from the known single counting rate. For the low multiplicities ( 1 to 3 ) the observed rate agreed with the predicted random multiplicities within the statistical uncertainty.

The exact number of neutrons that accompany spontaneous fission of a superheavy element and the shape of the neutron distribution are not yet known. Therefore, we cannot calculate exactly the probabilities associated with detecting an event with multiplicity $\mathrm{N}$ or more neutrons. However when the system operates with $\sim 67 \%$ efficiency and on the average 10 neutrons are emitted the probability of detecting four or more following a trigger by the first neutron is $\geqslant 60 \%$, depending somewhat on the shape of the assumed distribution. We have chosen then to report the results as the number of events having multiplicity four or greater. We related this to the number of atoms in the sample to obtain the half life. The half lives can be compared directly with the results of Flerov et al. ${ }^{2)}$

In Table I we present some results obtained in the various measurements. The results on the lead and the tungsten samples are rather close. In the case of tungsten it is reasonable to assume that its homologue ekatungsten would be too short lived to exist in nature. Therefore, the excess high multiplicity events present both in $\mathrm{W}$ and $\mathrm{Pb}$ can be assumed to come from the interaction of $\mu$-mesons with these heavy nuclei. Calculations based on the estimated flux and known cross sections confirm this assumption.

In obtaining the results described above, events following very large electronic pulses were rejected because the system was saturated by the large pulses. This caused the rejection of $\mu$-meson induced events with large multiplicities whenever the $\mu$-meson passed through the liquid scintiliator. A $\mu-m e s o n$ loses $1.5-2.0 \mathrm{MeV} / \mathrm{cm}$ in the liquid, 1.e., 30-250 MeV 
Table I. Results of the Measlirenerts ${ }^{\mathrm{a}}$

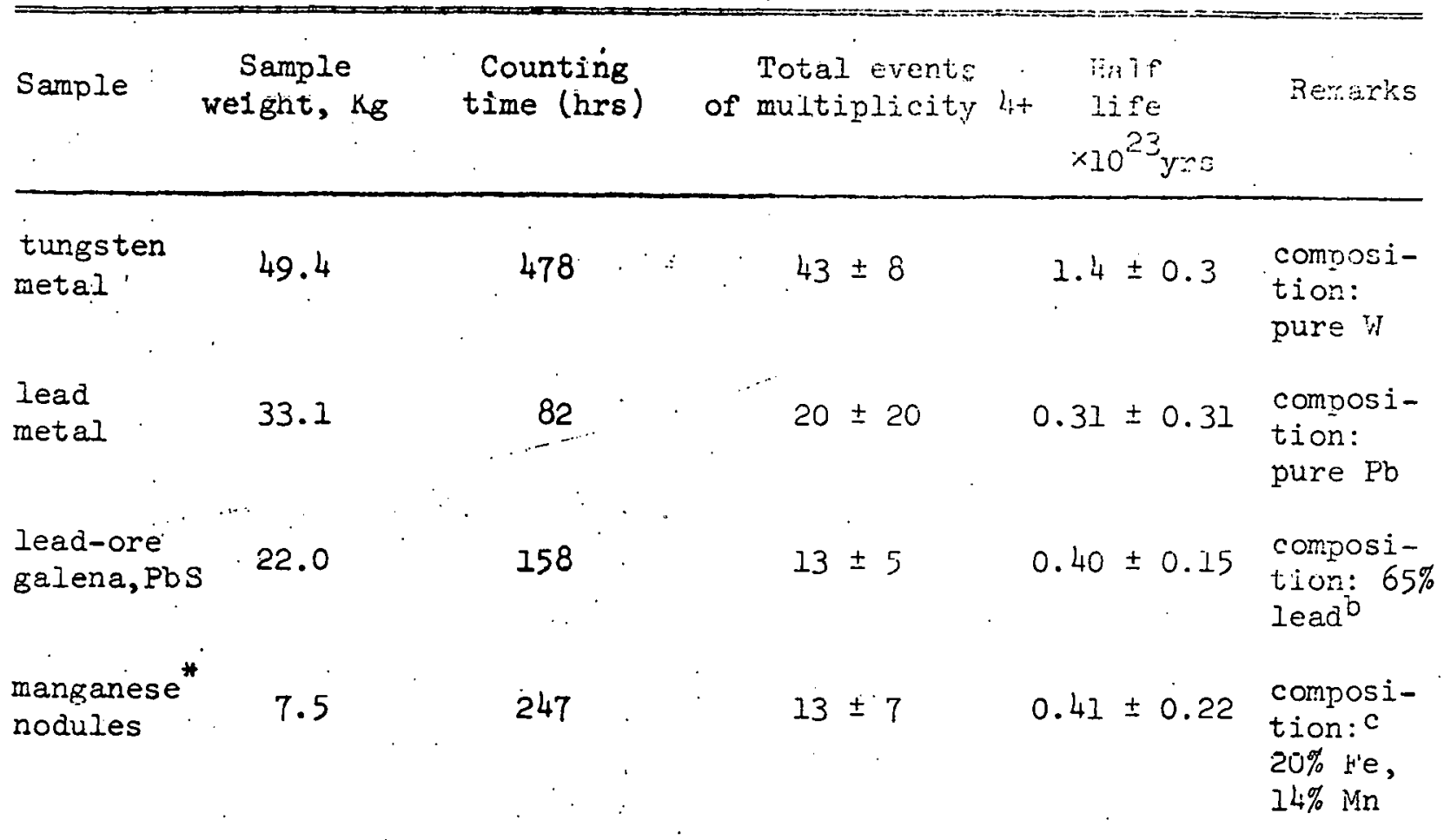

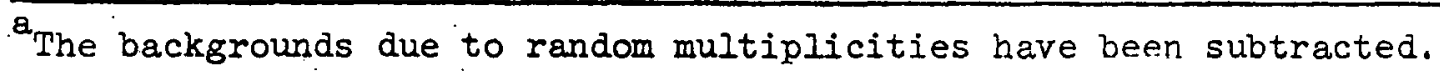

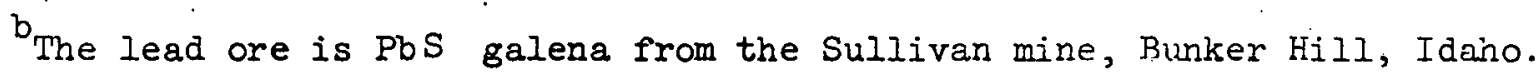

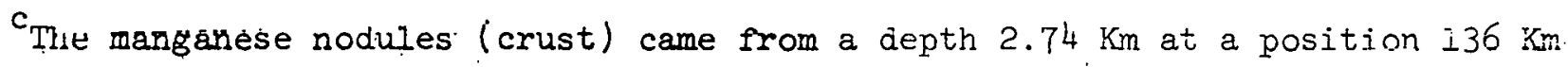
west of the Mid Atlantic ridge at $45^{\circ} \mathrm{N}$. More details are given by Fleischer et al. Phys, Rev, 184, 1393 (1969).

* This experiment was done with steel shielding placed around the apparatus. See text. 
when it passes through the tank, whereas the energy from relition capture garma rays amounts to $\sim 9 \mathrm{MeV}$.

Our lower limits which can be accounted for by the ccsnic ray background amounted to $\sim 3$ counts/day/50 $\mathrm{kg}$ heavy sample, of multiplicities 4 or more with 60-70\% neutron detection efficiency. This limit is equivalent to a half life of $\sim 10^{23} \mathrm{y}$ relative to the principal component of the samples. Within this limit we are unable to find thy evidence for the decay of "superheavy elements" in the samples that we have examined so far.

- These results are in agreement with the woris of Price ct al. ${ }^{3}$ ). that set a lower limit corresponding to a half life of $3 \times 10^{23}$ years for spontaneous fissions in the lead minerals by observing iission fragment tracks.

In Table I, the results are also given for a $\sim 7.5 \mathrm{~kg}$ sample of manganese nodules. These nodules contained $14 \% \mathrm{~m}$ and $20 \% \mathrm{Fe}$. The total number of events of multiplicity 4 or more was $13 \pm 7$ in a run of 247 hours length. On the basis of the total number of atoms of $M n$ and $F e$ taken together the half life limit is $4 \times 10^{22}$ years: The measurement of manganese nodules was performed after surrounding the apparatus with steel shielding of thickness $5 \mathrm{~cm}$. The effect of the shielding is discussed below.

In the later experiments steel shieiding was introduced around the apparatus in order to reduce the effect of backsyound gamma raciation from the surrounding medium. As a result the single $y-n$ courting rate was reduced from $\sim 650$ counts per sec to $\sim 250$ count $\therefore=$ rec. This reduction has the desirable effect of reducing the acciaental rite of aner multiplicity events: However, we found that the aadition of tile sielding had 
the undesirable effect of increasing the $\mu$-meson background. The $\mu$-mesons appeared to produce events of high neutron multiplicity in the shielding. Sulle of these events are produced by muons which do not pass through the tank. These events could therefore not be eliminated from the data.

After introducing the shielding, we also attempted to reduce the cosmic ray background by placing a liquid scintillator system above the main tank as indicated in Fig. 1. In this case muons coming from the vertical direction pass through the scintillator and produce large identifiable pulses which were used to remove associated high multipli sity pvents Which appear in the main tank, Also the $\mu$ meoono pasing thruigl lle large tank produce a similar large identifiable pulse (30-250 MeV) that was used to remove associated high multiplicity evenls. Even with these systems in operation we were not able to reduce the background below the level. which existed before the shielding was installed.

It now appears that the sensitivity of our apparatus can only be increased significantly by placing it much deeper underground where the $\mu$-meson flux is proportionately decreased. Perhaps an improvement by a factor of 10 to 50 could be obtained in this way. REFERENCES

I. a. V. J. Ashby, H. C. Catron, L. I. Newkirk, and C. J. Taylor, Pliys: Rev. 111, 616 (1958).

b. G. Chodil, R. C. Jopson, Hans Mark, C, D. Swift, R. G. Thomas, and M. K. Yates, Nucl. Phys. A93, 648 (1967).

2: G. N. Flerov and S. A. Karamyan, paper presented at the International Mendeleev Congress, Turin, 1969; report of Joint Institute for Nuclear Research, Dubna, JINR-P6-4902.

3. P. B. Price, R. L. Fleischer, and R. T. Woods, Phys. Rev. C I, 1819 (1970): 
This report was prepared as an account of Government sponsored work. Neither the United States, nor the Commission, nor any person acting on behalf of the Commission:

A. Makes any warranty or representation, expressed or implied, with respect to the accuracy, completeness, or usefulness of the information contained in this report, or that the use of any information, apparatus, method, or process disclosed in this report may not infringe privately owned rights; or

B. Assumes any liabilities with respect to the use of, or for damages resulting from the use of any information, apparatus, method, or process disclosed in this report.

As used in the above, "person acting on behalf of the Commission" includes any employee or contractor of the Commission, or employee of such contractor, to the extent that such employee or contractor of the Commission, or employee of such contractor prepares, disseminates, or provides access to, any information pursuant to his employment or contract with the Commission, or his employment with such contractor. 
TECHIVLAL INFORMATION DIVISION

LAWRENCE RADIATION LABORATORY

UNIVERSITY OF CALIFORNIA

BERKELEY, CALIFORNIA 94720 